\title{
Depressão pós-parto e afetos predominantes na gestação, parto e pós- parto
}

\author{
Mariane Teixeira de Carvalho \\ Miria Benincasa
}

\section{RESUMO}

O objetivo deste estudo foi comparar os afetos da mãe nos grupos com e sem depressão. Trata-se de uma pesquisa qualitativa, exploratória, com delineamento de quatro estudos de caso. A pesquisa foi realizada na residência das participantes e a amostra foi constituída por quatro mulheres do Estado de São Paulo, sendo duas que tiveram depressão pós-parto e duas que não tiveram. Os instrumentos utilizados foram à Entrevista Semidirigida, um Questionário Sociodemográfico e a Escala de Depressão Pós-Parto de Edinburgo, aplicados na residência das participantes. Os resultados foram apresentados a partir da análise de conteúdo e discutidos conforme a literatura especializada, revelando que este é um período de sentimentos ambivalentes em relação a si mesma, à gestação, às relações sociais e ao futuro. Independente da existência ou não do diagnóstico de depressão, houve necessidade de enfrentamento de conflitos individuais e sociais em todas as participantes durante todo o ciclo gravídico puerperal. Durante o período gestacional, todas as participantes passaram pelo processo de pré-natal, no entanto, as equipes se concentraram, exclusivamente nas alterações fisiológicas, negligenciando os aspectos sociais e psicológicos, culturais. Sugerese intervenções voltadas à promoção da saúde integral de mulheres durante o ciclo gravídico puerperal.

Palavras-chaves: depressão pós-parto; puerpério; afetos positivos e negativos; gestação; violência obstétrica.

\section{ABSTRACT \\ Postpartum depression and predominant affections in gestation, partum and postpartum}

This study aims to compare the affections of the mother in the groups with and without depression. This is a qualitative, exploratory research, with the outline of four case studies. The survey was conducted at the participants' residence and the sample consists with four women from state of São Paulo, Brazil, two of which have a postpartum depression and two that have not. Thus, three instruments are applied: Semi Structured Interview, Sociodemographic Questionnaire and Edinburgh Post-natal Depression Scale - EPDS, applied in the residence of the participants. The results were presented from the content analysis and discussed according to the literature, revealing that this is a period of ambivalent feelings about herself, gestation, social relations and the future. Regardless of the existence or not of the diagnosis of depression, there was the need to confront individual and social conflicts in all participants throughout the puerperal pregnancy cycle. During the gestational period, all the participants went through the prenatal process, however, the teams focused exclusively on the physiological changes, neglecting the social and psychological, cultural aspects. It is suggested interventions aimed at promoting the integral health of women during the puerperal pregnancy cycle.

Keywords: postpartum depression; puerperium; affect positive and negative; pregnancy; obstetric violence.

\section{Sobre os Autores}

M. T. C.

orcid.org/0000-0003-48355-

3190

Universidade de Taubaté -

Taubaté, SP

marianetcarvalho@hotmail.com

M. B.

orcid.org/0000-0003-1034-6999 Universidade Metodista de São Paulo - São Bernardo do Campo, SP

miria.benincasa@gmail.com

\section{Direitos Autorais}

Este é um artigo de acesso aberto e pode ser reproduzido livremente, distribuído, transmitido ou modificado, por qualquer pessoa desde que usado sem fins comerciais. 0 trabalho é disponibilizado sob a licença Creative Commons CCBY-NC. 


\section{W'INTERACÃO EM ET. PSICOLOGIA}

Na gravidez, a mulher passa por intensas alterações fisiológicas capazes de envolver tanto modificações hormonais quanto transformações corporais, psicológicas, sociais e ocupacionais. Autores nacionais e internacionais (Greinert \& Milani, 2015; Meltzer-Brody, 2015; Bell \& Anderson, 2016; Dennis \& Dowswell, 2013) identificam a presença de angústias e ansiedades relacionadas à necessidade de adaptação aos diversos papéis e demandas relacionadas ao período perinatal.

Considerando todas essas mudanças, que incluem os vários setores da vida, o período gravídico-puerperal promove a vulnerabilidade psicológica, propícia ao surgimento de depressão pós-parto e de outras patologias. Nesse caso, é importante compreender os aspectos emocionais e relacionais que circulam a gravidez na tentativa de prevenir quadros psicopatológicos ou minimizar sua sintomatologia (Greinert \& Milani, 2015; Meltzer-Brody, 2015; Dennis \& Dowswell, 2013).

A depressão pós-parto, também designada como depressão puerperal, depressão maternal ou depressão pósnatal, consiste em uma agitação emocional, relacionada ao humor e às reações presentes nas mulheres após o momento do parto (Bell \& Anderson, 2016; Dennis \& Dowswell, 2013; Coutinho \& Saraiva, 2008)

A literatura científica da área verifica a necessidade da avaliação precoce, ainda no período gestacional, indicando fatores de risco e de proteção presentes na vida da mulher grávida e de sua rede de apoio (Coutinho \& Saraiva, 2008; Negron, Martin, Almog, Balbierz, \& Howell, 2013). Este olhar atento e especializado, em posse dos indicadores necessários, permite a elaboração de intervenções preventivas, informativas e promotoras de saúde (Coutinho \& Saraiva, 2008; Negron, Martin, Almog, Balbierz, \& Howell, 2013).

Nos países ocidentais, a prevalência da depressão pósparto é de 13 a 19\% das mulheres. De acordo com a American Psychiatric Association - APA (2013), um episódio depressivo maior, que ocorre na gravidez ou 4 semanas após o nascimento do bebê, é considerado depressão com início perinatal. Os padrões de diagnóstico variam, mas muitos definem a ocorrência da depressão pós-parto a qualquer momento durante o primeiro ano de vida do bebê, e especialmente dentro de seis meses após seu nascimento (Greinert \& Milani, 2015; Meltzer-Brody, 2015).

A depressão pós-parto não pode ser confundida com outra alteração do humor denominada baby blues ou tristeza materna, que é mais prevalente e com sintomatologia mais leve e tende a se manifestar até seis semanas após o parto. Dentre os fatores de risco conhecidos na depressão pósparto destacam-se: histórico de psicopatologia, depressão ou ansiedade durante a gravidez, pouco apoio social e eventos estressantes da vida, e pouca exploração em relação ao vínculo entre a experiência do parto e a depressão pós-parto (Bell \& Andersson, 2016).

Existem evidências significativas de que eventos associados ao nascimento aumentam o risco de depressão pós-parto tais como, intervenções, complicações e atraso do contato mãe-bebê após nascimento. Estudos avaliando a percepção de mulheres sobre a experiência do nascimento identificam que são priorizados e valorizados: respeito, privacidade, suporte, inclusão na tomada de decisões e sentimento nutrido (Bell \& Andersson, 2016; Maimburg \& Væth, 2015; Negron et al., 2013; Diniz et al., 2015).

O objetivo desta pesquisa foi comparar os afetos predominantes durante o período gestacional, parto e pósparto entre duas mulheres que tiveram e duas que não tiveram diagnóstico de depressão pós-parto. 0 objetivo secundário foi verificar a presença de fatores de risco biológicos, psicológicos e nas relações durante a assistência ao parto e pós-parto.

\section{MÉTODO}

Este estudo é um recorte de uma pesquisa financiada pela Fundação de Amparo à Pesquisa do Estado de São Paulo (FAPESP) intitulada "Cesárea Eletiva, Violência Obstétrica e Parto Humanizado: o legado destas intervenções para a vida emocional da mulher" (Benincasa, 2014). Trata-se de uma pesquisa exploratória, com análises qualitativas e delineamento em quatro estudos de caso.

\section{PARTICIPANTES}

A população foi composta por quatro mulheres, sendo duas que tiveram depressão pós-parto e duas que não tiveram. Os critérios para a inclusão na amostra além dos determinados acima foram: a) ter passado pelo processo de parto há pelo menos 6 meses e no máximo 36 meses; b) ser o único filho(a); c) estar em uma relação conjugal estável. As participantes foram identificadas por nomes fictícios de flores: Margarida, Girassol, Hortência e Violeta, e todas as pessoas citadas por elas durante as entrevistas também tiveram seus nomes personalizados por flores.

\section{INSTRUMENTOS}

Os instrumentos utilizados foram a Entrevista Semiestruturada, o Questionário Sóciodemográfico (Benincasa, 2014) e a Escala de Depressão Pós-Parto de Edinburgo - EPDS. O questionário sociodemografico foi composto por questões objetivas em que foram perguntados 


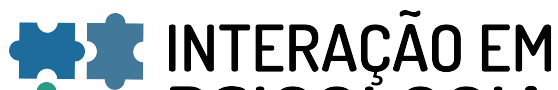 ET PSICOLOGIA}

dados pessoais, financeiros, ocupacionais. A Escala de Depressão Pós-Parto de Edinburgo (EPDS) desenvolvida na Grã-Bretanha é um instrumento de autoavaliação formado por 10 itens referentes aos sintomas depressivos decorrentes ao pós-parto (Malloy-Diniz, Schlottfeldt, Figueira, Neves, \& Corrêa, 2010). Foi traduzida e adaptada para a população brasileira.

Este estudo contemplou todos os procedimentos éticos em pesquisas com seres humanos definidos pela Resolução 466/2012, obtendo aprovação do Comitê de Ética em Pesquisa pela Universidade Metodista de São Paulo ( $n^{\circ}$. 1.814.472).

\section{PROCEDIMENTOS DE COLETA DE DADOS}

0 acesso às participantes foi por meio do método Bola de Neve (Biernack \& Waldorf, 1981), que consiste em buscar uma participante que indica as demais. Foram realizados dois encontros de 60 minutos com cada. No primeiro encontro foi realizada e gravada a Entrevista Semiestruturada. No segundo foram aplicados o Questionário Sociodemográfico e a EPDS. A coleta de dados foi realizada na residência das participantes, em data e horários prédeterminados e confortáveis para as mães e pesquisadora.

\section{PROCEDIMENTOS DE ANÁLISE DE DADOS}

As entrevistas foram transcritas e, assim, realizada a análise de conteúdo (Campos, 2004; Oliveira, 2008). De acordo com Oliveira (2008), alguns conceitos sustentam o desenvolvimento da análise de conteúdo, permitindo instrumentalizá-la. Inicialmente foi feita uma pré-análise, buscando as primeiras hipóteses ou questões norteadoras relacionadas aos objetivos do trabalho. Estas foram organizadas em indicadores, ou seja, unidades de categorização, buscando semelhanças e contrastes ao tema investigado. Posteriormente foram identificadas unidades de registro, buscando descrever e explorar todo seu conteúdo. As unidades de registro que se relacionam foram agrupadas em uma categoria e distribuídas em subcategorias. O questionário sociodemográfico foi necessário para caracterizar a amostra quanto à idade da mãe, renda, escolaridade e estado civil. A escala de Depressão Pós-Parto de Edinburgo (EPDS) foi utilizada como parâmetro para indicação da análise de conteúdo.

\section{RESULTADOS E DISCUSSÃO}

Nos resultados e discussão será apresentada, inicialmente, a caraterização da amostra e, posteriormente, as categorias definidas pela análise de conteúdo, ou seja: Categoria1: Afetos - positivos e negativos, Subcategorias: Gestação, Parto e Pós-parto; Categoria 2: Fator de risco, Subcategorias: Biológico, Psicológico e Relação com a Equipe. Cada Subcategoria será apresentada por frases emblemáticas de cada participante e posterior discussão.

\section{CARACTERIZAÇÃO DA AMOSTRA}

Segundo os dados coletados apresentados na Tabela 1, observa-se o grau de instrução. Todas as participantes revelaram instrução mínima de terceiro grau completo. Segundo pesquisa do SEADE (Brasil, 2010) entre 2000 e 2010, o porcentual de pessoas com ensino superior completo no mercado de trabalho passou de $11,7 \%$ para $15,0 \%$ da População Economicamente Ativa e este crescimento foi mais significativo entre mulheres. Por outro lado, estas participantes representam uma parcela privilegiada da população brasileira quanto ao grau de instrução, e estendese a isso o modelo de assistência ao parto. Todas as participantes foram assistidas, ou no pré-natal ou no parto pela saúde suplementar, ou seja, através de convênio médico.

\section{CATEGORIA 1: AFETOS - POSITIVOS E NEGATIVOS}

\section{Subcategoria Gestação}

Participante 1: Margarida

“Cravo (marido), nossa, ele me apoiou cem por cento. Os

Tabela 1. Caracterização da amostra

\begin{tabular}{llllll}
\hline Participante & $\begin{array}{l}\text { Idade } \\
\text { (anos) }\end{array}$ & Escolaridade & Renda & Estado civil & Idade do bebê \\
\hline Margarida & 27 & Superior Completo & 1 a 3 salários mínimos & Casada & 2 anos e 8 meses \\
Girassol & 23 & Médio Completo & 3 a 5 salários mínimos & Casada & 1 ano e 1 mês \\
Hortência & 40 & Pós-Graduação & 6 a 10 salários mínimos & Casada & 2 anos \\
Violeta & 27 & Superior Completo & 1 a 3 salários mínimos & Casada & 1 ano e 5 meses \\
\hline
\end{tabular}




\section{W'INTERACÃO EM ET PSICOLOGIA}

pais, a irmã dele mais velha, todos. Mal tava grávida ela já conversava com o Hibisco na minha barriga e todo mundo vinha e beijava minha barriga. Super me apoiou."

"Ai daí eu comecei a chorar. Falei 'mãe eu não acredito, mãe eu to grávida mesmo'. Ai caiu a minha ficha. Ai eu vi que a minha vida tava pela vida dele. Ai eu falei 'nossa, agora é pra valer'."

\section{Participante 2: Girassol}

"Não foi planejada a gestação. Foi um susto tremendo, eu não aceitava estar grávida, não queria de jeito nenhum porque eu tinha muito medo. Então foi bem difícil assim pra mim aceitar a gestação, eu comecei a aceitar acho que já tava com seis meses. Não queria ter, eu nunca quis ter filho."

\section{Participante 3: Hortência}

"Eu planejei, não conseguia, eu tive problema de infertilidade."

"Foi uma gravidez muito esperada, então tudo girou em torno da gravidez."

“Feliz, a maternidade para mim é complicado, né?! Já começo a chorar antes. Feliz por que tinha acabado o sofrimento, 5 anos tentando, aí eu senti que minha vida iria mudar dali para frente."

\section{Participante 4: Violeta}

"Todo mês, quando atrasava um dia eu já comprava um teste (risos). Pra saber se estava ou não. E bastante ansiosa né. Aí quando eu descobri, quando chegou setembro, que eu descobri a gente (marido) ficou muito feliz."

"Mas eu fiquei bastante nervosa e também em relação a sexualidade, eu não queria fazer nada, durante a gestação."

"Sempre tive certeza de que teria um menino, tanto eu como ele (companheiro). Quando soubemos que era menina, o mundo caiu. Não estávamos preparados para sermos pais de menina."

Percebe-se no relato das participantes que a gestação é um evento importante nas experiências familiares (Silva \& Silva, 2009; Meltzer-Brody, 2015). Silva e Silva (2009) consideram que nesse período emerge uma situação de crise evolutiva que pode ser verificada explicitamente nas participantes Margarida e Girassol, por não terem planejado a gravidez e se deparam com dificuldades frente às mudanças inesperadas desta nova realidade.
Um aspecto importante vivenciado no relato de Violeta corresponde à ansiedade frente a descoberto do sexo do bebê, que sempre esperou um menino, mas teve uma menina, desencadeando afetos negativos em relação ao bebê. 0 sexo do bebê é uma informação de fundamental importância durante a gestação por carregar muitos simbolismos pessoais, familiares e culturais (Piccinini, Gomes, Moreira, \& Lopes, 2004). Mesmo que os pais não explicitem as dúvidas quanto ao sexo do bebê, conhecê-lo antes do nascimento permite reduzir as idealizações (Piccinini et al., 2004).

No relato de todas as participantes se notam sentimentos ambivalentes durante a gestação, ou seja, a presença simultânea de afetos positivos e negativos voltados para o mesmo objeto, seja ele o marido, o bebê, a equipe de saúde, a família etc. Segundo alguns autores, (Silva \& Silva, 2009; Meltzer-Brody, 2015; Dennis \& Dowswell, 2013), as oscilações de humor podem estar associadas com as próprias alterações metabólicas e hormonais específicas da gestação. Meltzer-Brody (2015) indica que 67\% dos casos de Depressão pós-parto apresentam sintomatologia durante a gestação.

Nota-se que a maior incidência de afetos positivos entre as participantes está associada à presença de uma rede de apoio confiável, seja representada pelo marido ou pela família e/ou amigos. A literatura aponta que este suporte que é fundamental nesse momento, sendo determinante para o processo de adaptação às novas condições impostas pela maternidade (Silva \& Silva, 2009, Piccinini et al., 2004; Dennis \& Dowswell, 2013; Negron et al., 2013).

\section{Subcategoria Parto}

\section{Participante 1: Margarida}

"A hora que ele saiu, já bateu na bundinha dele, ele já começou a chorar, eu comecei a chorar junto."

"Eu tive que ir no hospital escola público, essa foi a única parte ruim. Eu fiquei super insegura, não sabia o que ia acontecer e eu ia ter um parto normal. Eu queria um parto normal."

\section{Participante 2: Girassol}

"Ah sobre o parto, a expectativa tipo foi bem melhor do que eu achava, porque eu tive no hospital escola, e eu não tenho do que reclamar de lá. Fui muito bem atendida."

“(...) o parto normal eu já sai no outro dia, já andei, tipo já tomei banho sozinha já, então pra mim foi super de boa o parto normal, teria outro, o meu medo é engravidar e ir pra uma cesárea agora né, então.."

Participante 3: Hortência 


\section{W'INTERACÃO EM ET. PSICOLOGIA}

"Ahh, quando estava chegando o parto, fiquei chocada com a cesárea, (...) falei, não tem nada romântico nisso (...) você vai andando até a mesa e chega lá e toma uma anestesia, (...)decepcionada, o negócio é muito mecânico né?!"

“Estava sozinha em um lugar gelado."

"Foi bonito quando eles trouxeram pra mim, quando eu já estava no quarto, que aí eu já tive contato com o Narciso... foi o momento da amamentação."

\section{Participante 4: Violeta}

"A enfermeira era muito calma, eu pedia ajuda para ela e elas falavam 'calma mãezinha, ta quase chegando a hora de você ver a sua bebê'. Bem calma."

"Nossa, foi legal, foi gostosa, mas devido à dor eu não fiquei assim tão alegre, (...) a enfermeira (...) mostrou ela para mim e falou assim 'mãezinha dá um beijinho nela', porque eu só tinha olhado ela, mas estava tão desfalecida (risos) (...)."

Para alguns autores (Lopes, Donelli, Lima, \& Piccinini, 2005; Tesser, Knobel, Andrezzo, \& Diniz, 2015), diversos fatores influenciam a experiência do parto, entre eles o tipo de parto e as intervenções obstétricas realizadas neste momento, as vivências durante a gestação e as esperanças mantidas em relação ao parto e ao bebê.

Nesse sentido, é possível observar durante a entrevista, que as expectativas da participante Margarida era vivenciar o parto normal e, ao realizá-lo, ficou emocionada ao ter o primeiro contato com o bebê. Porém, devido às condições do hospital público, essa experiência foi marcada por afetos negativos frente à insegurança que sentiu. 0 mesmo ocorreu com as participantes Girassol, Hortência e Violeta, que relatam afetos negativos, vivenciado por sentimentos de nervosismo e de preocupação, apresentando dúvidas sobre qual parto iria escolher.

Sendo assim, os receios mais frequentes entre as participantes, no período da gravidez se relacionam com as fantasias sobre parto. Esta associação de sentimentos ambivalentes, e muitas vezes negativos com a hora do parto é amplamente apresentada pela literatura (Lopes et al., 2005; Negron et al., 2013).

Tal experiência se torna tão marcante que durante anos os sentimentos vivenciados com o nascimento do bebê são lembrados em mínimos detalhes. O parto, em sua forma natural, não é um evento neutro, pois mobiliza grandes níveis de ansiedade, medo, excitação e expectativa, e sua intensidade auxilia na reconstrução da identidade da mulher. Assim, por diversas razões o parto é um momento importante na transição para a maternidade, primeiro por ser o momento em que mãe e bebê irão se encontrar frente a frente, e em seguida, é o momento em que a mulher encontra com o bebê real, diferente daquele que era imaginário, ou seja, idealizado na gestação (Lopes et al., 2005; Ohoka, et al., 2014).

\section{Subcategoria Pós-Parto}

\section{Participante 1: Margarida}

“Na parte da manhã minha mãe me ajudava, mas depois também ela ia embora, (...). Os dois primeiros meses pra mim foram muito difíceis. (...) eu não dormi por dois meses e meio. Eu acordava de quarenta e quarenta minutos."

“Pra tomar banho eu não tinha coragem de deixar ele no carinho porque ele já chorava. Dai esperava alguém chegar pra ele sentir o calorzinho, pra mim conseguir fazer minhas coisas (...) Mas por dois meses e meio foi muito difícil."

\section{Participante 2: Girassol}

“(..) eu não quero ninguém em casa. Eu quero que a gente se vire, a gente aprenda a fazer as coisas. (...) como ele tirou a licença paternidade, ele ficou em casa comigo, me ajudou. 0 primeiro banho em casa, foi ele quem deu. (...) Então tudo é o pai. Ele quer fazer, ele quer dar comida, tudo. Primeira frauda quem trocou em casa foi ele também."

"A amamentação, ó foi bem difícil. Bem difícil, eu chorava muito para amamentar, porque ele machucou muito. Os dois peitos ficaram muito machucados. Chegava a pingar sangue de tão machucado que ficou, (...) e eu dava mamá pra ele mordendo um pano, e chorava, que eu soluçava pra mim conseguir dar mamá pra ele."

“Todo mundo passa pra você que é mil maravilhas, que é lindo tudo. Só que na hora eu não conseguia ver tudo aquilo. Porque eu não dormia, eu não comia, eu estava com os seios super machucados, chegava a sangrar."

\section{Participante 3: Hortência}

"A volta pra casa que começa o meu drama. Por que eu estava super bem no hospital. Eu estava eufórica. Mas, na hora que eu botei os pés em casa, eu me transformei."

“Eu cheguei em casa e só tinha vontade de chorar (...) ele só chorava. E assim..eu comecei a ficar completamente transtornada, não acredito. Por que eu fui inventar de ter esse filho?! Aonde eu fui me enfiar (...) eu fui ficando muito ruim (...). Eu olhava pra ele e falava 'eu não gosto desse menino' (choro) o que esse menino tá fazendo aqui, 


\section{H*' INTERACÃO EM LF PSICOLOGIA}

na minha vida? Desculpa. Eu falava 'mãe eu não tô bem, eu não gosto dele, eu não gosto de ficar perto dele'."

"No começo eu sentia muita coisa assim, além dos sintomas ruins com relação ao bebê. Eu sentia muita ansiedade, dor de cabeça, eu não tinha fome, diarréia, eu tinha tudo quanto é coisa assim, eu fui melhorando aos poucos (...)."

\section{Participante 4: Violeta}

"Conto muito com meu esposo né. Ele trabalha, eu não. Então eu procuro marcar as coisas sempre após o horário que ele chega do serviço."

"Ele foi e é um parceirão, porque senão, não sei o que seria de mim."

"Então, nunca ninguém tinha me falado que era difícil assim, pra mim né, que sempre a gente vê escrito só coisas bonitas, na internet, as pessoas também próximas não fala muito isso pra você."

Conforme consta nos relatos das quatro participantes desse estudo, os afetos negativos predominantes no pósparto ressaltam as dificuldades encontradas frente aos cuidados e adaptação com o bebê, onde o medo era presente nos primeiros contatos.

Vários autores (Lopes et al. 2005; Oliveira, Rodrigues, Guedes, \& Felipe, 2010; Dennis \& Dowswell, 2013), avaliando os sentimentos de mulheres durante o trabalho de parto verificaram que em todas as participantes esta ambivalência se torna presente, podendo haver predominância maior de sentimentos positivos ou negativos. Tais autores confirmam ainda não haver diferenças significativas na presença de sentimentos ambivalentes entre diferentes tipos de parto, bem como entre classes sociais, variável que não foi considerada no presente estudo. Observa-se, entre as participantes, a utilização da rede de apoio para lidar com os afetos negativos e situações-problema.

Para alguns autores (Konradt et al., 2011; Meltzer-Brody, 2015; Dennis \& Dowswell, 2013; Negron et al., 2013), o período do pós-parto exige uma maior prevenção clínica, devido à vulnerabilidade biológica que a mulher se encontra. Além desta assistência clínica, é indispensável assumir um olhar atencioso às questões biopsicossociais apresentadas pelas mulheres nesse período. Assim, a rede de apoio, composta pela família, companheiro e/ou amigos, adquire grande importância nas vivências da mulher desde o momento da gestação até o pós-parto, como é possível perceber a partir dos dados obtidos durante os relatos das participantes, que de modo geral a predominância dos afetos positivos no período do pós-parto expõe a rede de apoio como fator principal.

No período do pós-parto, identificou-se a presença da depressão nas participantes Hortência e Violeta, na qual de acordo com os afetos negativos vivenciados, apresentaram com frequência sentimento de ansiedade e choro. Iniciando assim um conflito entre a realidade e a expectativa.

Nos quadros de depressão pós-parto são identificados sintomas de irritabilidade leve ou severa, tristeza, ansiedade, oscilação de humor e fadiga. Sua incidência pode ser duradoura e com sintomas intensos, o que impossibilita a mãe de realizar as tarefas diárias nesse período (Konradt et al., 2011; Meltzer-Brody, 2015; Dennis \& Dowswell, 2013; Negron et al., 2013).

Nesse sentido, a rede de apoio, bem como a boa relação com o marido, apresentada pelas participantes, tornam-se cada vez mais fundamentais na vida das puérperas que vivenciam este período com dificuldade e insegurança, pois o suporte social corresponde ao suporte emocional ou prático dado pela família e/ou amigos através de afeto, companhia, assistência e informação, fazendo com que a mulher se sentisse amada, cuidada, valorizada e segura. Os resultados deste estudo corroboram os achados da literatura que apontam como imprescindível o envolvimento da família e dos amigos neste período como fator protetor para a depressão pós-parto (Dennis \& Dowswell, 2013; Negron et al., 2013). Essa assistência afetiva associada a técnicas terapêuticas contribui para a melhora nesse quadro em que as pacientes se encontram (Konradt et al., 2011; Dennis \& Dowswell, 2013; Negron et al., 2013).

\section{CATEGORIA 2: FATOR DE RISCO}

\section{Subcategoria Biológico}

\section{Participante 1: Margarida}

"Teve uma vez que eu tava com muita dor, muita dor até pra fazer urina, até pensei que fosse uma infecção de urina, fui no ginecologista e a ginecologista me falou que eu tava com uma infecção no colo do útero.

"Tomei remédio durante os quatro meses. Ai na hora que eu descobri, passei muito mal. Daí eu parei de tomar o remédio."

\section{Participante 2: Girassol}

“Eu não chegava a vomitar, mas eu não conseguia comer nada, porque eu passava o dia inteiro super enjoada, com mal estar, com enxaqueca, daquelas terríveis. Até no dia que eu decidi sair do serviço, quando eu saí do serviço eu acho que tava com quatro meses, que foi até quando eu passei mal, que até com quatro meses e meio eu passei 


\section{H* INTERACÃO EM LF PSICOLOGIA}

mal (...). Engordei vinte e cinco quilos da gravidez, porque eu comia muito."

\section{Participante 3: Hortência}

"Fiz tratamento durante 5 anos. Fiz duas inseminações, uma fertilização, não consegui. Aí eu tentei na fila da adoção, demorei um ano na fila da adoção, quando eu fui aprovada no cadastro de adoção, eu fiquei grávida do Narciso (...). Eu tive todos os sintomas de gravidez, eu tive, eu enjoei até o terceiro mês. Só não tive azia, que as mulheres falam que sentem.. mas eu tive tudo, dor nas costas, dor, eu tinha câimbras, inchaço, adormecia minha mão, amoite assim.. as pontas dos dedos."

\section{Participante 4: Violeta}

“Eu tive bastante enjôo. Eu trabalhava né, então de manhã passei muita vergonha, nos ponto de ônibus, porque vomitava mesmo (...). Tinha bastante dor de cabeça, então tava sempre indo pro hospital tomar medicação. Fiquei internada, porque eu tive infecção de urina. Ela inclusive veio prematura com oito meses, de resto, foi tranquilo."

De acordo com os dados obtidos, nos relatos de Hortência e Violeta, destacam-se afetos negativos em função da presença da depressão pós-parto, relacionada ao histórico familiar da depressão. Este resultado poderia ser inserido tanto nos fatores de risco biológicos quanto psicológicos. Optou-se pela subcategoria biológico pela ênfase das participantes em relatarem histórico familiar deste transtorno.

Os fatores de risco para a depressão pós-parto descritos na literatura, além da hipótese genética são: vivências de eventos estressantes, relação marital precária, pouco suporte social, história de depressão ou ansiedade na gestação, histórico familiar de depressão, entre outros (Konradt et al., 2011; Silva, Araújo, Araújo, Carvalho, \& Caetano, 2010; Saraiva \& Coutinho, 2007; Schardosim \& Heldt, 2011; Maimburg \& Væth, 2015). Na participante Hortência, poucos fatores de risco são apontados além do histórico familiar e a infertilidade. Violeta, entretanto, refere-se a situações familiares estressantes e recorrentes.

Diversos estudos (Schardosim \& Heldt, 2011; Schwengber \& Piccinini, 2003; Maimburg \& Væth, 2015) demonstram a presença de uma associação do episódio da depressão pósparto a ausência de suporte social, bem como o não planejamento da gestação, o nascimento prematuro, a dificuldade na amamentação e as dificuldades no momento do parto, como acontece com as participantes deste estudo identificadas com depressão pós-parto.

De acordo com as referências encontradas, as participantes Margarida e Girassol, que não tiveram depressão pós-parto, ao serem comparadas com as participantes com este diagnóstico, também apresentaram alguns fatores de risco, tais como: as dificuldades no momento da amamentação e no momento do parto. Por outro lado, o mal-estar físico durante a gestação foi mais frequente entre as participantes que não tiveram diagnóstico de depressão.

\section{Subcategoria Psicológico}

\section{Participante 1: Margarida}

"Única parte que a ginecologista me explicava, assim é que (...) os únicos riscos que poderia ter era de em uma das consultas até cinco meses, é descobrir se o bebê tem síndrome de Down ou não, microcefalia, que na época tava um negócio de microcefalia nos hospitais. Ai eu fiquei muito desesperada até minha próxima consulta."

\section{Participante 2: Girassol}

“Eu só comecei na verdade me cuidar assim, ter gosto de me cuidar, quando ele estava com uns oito, nove meses assim mais ou menos. Porque no começo era bem difícil eu me olhar no espelho, eu me achava horrível (...). Passei a gestação inteira nervosa porque eu não curti a gestação né, com medo, como que vai ser o parto."

\section{Participante 3: Hortência}

“Eu sempre achei que iria ter uma menina, aí descobri que iria ter um menino. Foi diferente para mim. Então, não me frustrei, só foi diferente sabe?! (...) Aí eu nossa (...) eu tenho que me preparar para ser mãe de um menino (...). Eu liguei pra minha médica e ela falou pra mim que eu estava ficando com depressão pós-parto e me deu um remédio, só que você precisa de receita. (...). A minha vontade era de sumir, de morrer, a minha vontade de acabar com ele era maior do que tudo."

\section{Participante 4: Violeta}

“Já eu não me achava bonita, eu fiquei meio, não queria tirar foto, num gostei não. Eu fiquei preocupada com as estrias (risos). Isso me deixou bastante preocupada (...). Ah, não foi nada fácil. Bem difícil. Até hoje, porque, assim eu vejo minha barriga. É, ficou parecendo um saquinho murcho. Acho que porque cresceu tanto né, e depois (...) aí ficou muito feia. Ai meu Deus!"

Nos resultados encontrados na categoria fatores de risco psicológicos, destacam-se predominância da preocupação com a autoimagem e com o corpo, identificada na participante Margarida; e a baixa autoestima, identificada na maior parte das participantes, Girassol, Hortência e Violeta.

Esses conjuntos de fatores indicam riscos psicológicos 


\section{H. INTERACÃO EM LF PSICOLOGIA}

muito frequentes durante o ciclo gravídico-puerperal. A presença destes sinais deve ser um mobilizador da equipe de saúde para manter um olhar integral da mulher e de todas as suas funções biopsicossociais (Dennis \& Dowswell, 2013; Konradt et al., 2011; Negron et al., 2013). As alterações hormonais e sociais podem acarretar manifestação de humor deprimido, perda de interesse ou prazer pelas coisas, baixa autoestima e diminuição da concentração que podem ser minimizadas por intervenções psicoeducativas durante este período (Konradt et al., 2011; Meltzer-Brody, 2015; Negron et al., 2013).

Como é possível observar, tanto a partir dos relatos quanto na construção bibliográfica, ao tratar da relação e do sentimento materno com o bebê, os afetos e os fatores de risco psicológicos influenciam na díade. As dificuldades de reconhecer o corpo e a forma como a aparência afeta as mães, surge até mesmo nas puérperas que tiveram sua gravidez planejada. Portanto, a atitude emocional e afetiva da mãe norteia os afetos apresentados pelo bebê, o que influencia na qualidade de vida do mesmo, visto que o amor e a afeição pelo bebê são destacados por serem os maiores interesses da mãe, que proporciona todas as experiências vitais necessárias, interligadas e caracterizadas a partir do afeto materno, na qual o bebê responde a mãe com a mesma afetividade (Borsa, 2007; Carlesso, Souza, \& Moraes, 2014).

\section{Subcategoria Relação com a Equipe}

\section{Participante 1: Margarida}

"Aí o Hibisco saiu né da sala de parto, tava tudo bem, daqui a pouco entra um milhão de estudante (...). Eu nervosa aberta, aí uma falou assim, 'você quer fazer um piquezinho na mulher?'. Porque como foi um parto normal, só que como eu não tinha muita abertura, daí eles tiveram que fazer cinco pontinhos a mais, quem ia me costurar era uma estudante (...). Não perguntaram pra mim não. A menina chegou na frente, 'não tem que fazer assim', 'tô fazendo certo? Tô fazendo certo?' Aí eu, como assim? Eu fiquei muito apavorada, porque como que uma estudante tava me costurando? Eu não sabia se aquilo lá ia ficar cicatriz. Eu não sabia como é que era. Não me explicaram."

\section{Participante 2: Girassol}

"Acho que foi quatro pontos que eu tomei. Então eu nem. foi bem, bem de boa mesmo, eu achava que seria um bicho de sete cabeças, do jeito que eu sou medrosa (...). Falei doutora eu tô com muita dor, aí ela foi e me aplicou uma raque, depois da raque eu não senti nada, assim, foi porque ela empurrou ele pra sair, porque eu não senti nada. Ela subiu assim, e empurrou pra ele sair. Porque vinha a contração, e ele apontava pra sair, na hora que ele tava pra sair, passava a contração e ele voltava. Então ele ficava indo e voltando."

\section{Participante 3: Hortência}

“E eu senti falta de não ficar pertinho assim... por que não teve né?! Foi bonito quando eles trouxeram pra mim, quando eu já estava no quarto, que aí eu já tive contato com o Narciso.. foi o momento da amamentação. Acho que depois de umas duas horas que eu vi o Narciso. E aí depois, depois foi muito tranquilo (...). Aí eu fiquei passando um pouco mais de tempo lá no pós-operatório. Acho que com medo de dar um trombo, né? E fiquei lá acho que um dia inteiro."

\section{Participante 4: Violeta}

"Já o médico, ele era um pouco mais grosso né. Inclusive quando estava na sala de cirurgia, eu não aguentava mais fazer força, ai ele falava 'vai Violeta, faz força', ai eu falei para ele, eu to fazendo, ele 'não você não está fazendo, tá falando comigo'. Ele era um pouco mais chatinho (...). Tanto que eu não sabia o que era isso. Ai antes do parto eu fiquei pesquisando algumas coisas, e descobri que tinha isso também. Inclusive falam que a gente tem que autorizar, mas não falaram nada pra mim disso dai, a respeito disso. Quando eu saí já estava ele falou para mim assim 'a gente tá dando uns pontinhos'. Então já tinha cortado."

Alguns autores (Velho, Santos, \& Collaço, 2014; Bell \& Anderson, 2016; Vliegen, Casalin, \& Luyten, 2014), ao realizarem uma revisão integrativa sobre a vivência do parto normal e do processo cirúrgico, verificaram que a aquisição de informações sobre o que está ocorrendo durante o parto e quais os procedimentos que serão feitos tendem a gerar sentimentos de confiança na parturiente, independentemente do tipo de parto realizado. Observa-se que a equipe que assistiu a estas gestantes não se ocupou em fornecer informações sobre as intervenções que estavam sendo realizadas e, segundo a hipótese dos autores supracitados, esta postura pode ter contribuído para o aumento da insegurança e do medo.

A negligencia, a falta de informação durante o parto ou a agressividade (grosseria relatada por Violeta) estiveram presentes em todos os quatro relatos, caracterizando-se a Violência Obstétrica, segundo as tipificações da Argentina e Venezuela (Belli, 2013; Tesser et al., 2015). A realidade vivida pelas participantes nâo é exclusiva desta amostra, mas de, pelo menos, $25 \%$ das mulheres que tiveram filhos nos últimos anos no Brasil (Diniz et al., 2015).

\section{CONSIDERAÇÕES FINAIS}




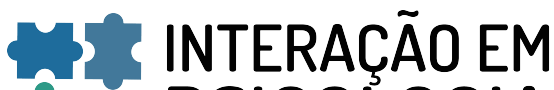 ET PSICOLOGIA}

O presente estudo discorre a respeito da depressão pósparto e apresenta o risco de adoecimento ou de surgimento de sintomas e sinais que diminuem a qualidade de vida e o bem-estar da mulher, o que dificulta a interação social, o apego e o vínculo com o bebê.

Para compreender as manifestações depressivas em suas diversas intensidades, foi apresentado como os afetos foram vivenciados durante esse período. A partir dessa compreensão, nota-se que os sintomas da depressão pósparto são manifestações afetivas, como por exemplo: tristeza a maior parte do dia todos os dias, pouco prazer nas atividades que desenvolve, distanciamento emocional, choro frequente, entre outros, mostrando ao leitor o estado afetivo dessa mulher.

Dentre as participantes, todas realizaram o pré-natal, ou seja, a equipe de saúde teve acesso a todas elas, porém se tivessem observado os sinais e conhecessem os fatores de risco, talvez o resultado fosse de maior bem-estar e a sintomatologia pudesse ter sido evitada. Verifica-se, entretanto, total falta de intervenção voltada à saúde integral da saúde da mulher, observando a mulher ela com ela mesma, com seu corpo, com seu marido, com sua gestação, com as redes de apoio, com a vida social, além dos cuidados físicos. Há uma tendência de biologizar a saúde, desconsiderando os fatores psicológicos, culturais e sociais, que podem contribuir fortemente para o processo de adoecimento e cura, tanto como fatores de proteção. Apesar de duas participantes apresentarem diagnóstico de Depressão Pós-Parto, observa-se que as quatro seriam beneficiadas de um olhar atento à sua saúde integral e aos sinais de desconforto emocional e social que foram emitidos durante todos o pré-natal.

Em suma, a incidência da depressão já é maior entre as gestantes do que entre a população normal, sendo um sinalizador para o desenvolvimento de políticas públicas voltadas à essa realidade. Portanto, o trabalho mostra a necessidade um olhar integral para a mulher com o objetivo de promover saúde e uma assistência generosa e adequada, não só para prevenir a Depressão Pós-Parto, mas também para aumentar a qualidade de vida, o bem-estar e a disponibilidade para estar com o bebê, com os benefícios e os prejuízos que esta relação impõe.

\section{CONTRIBUIÇÃO DE CADA AUTOR}

M. T. C. foi responsável pela coleta e análise dos dados apresentados neste manuscrito. M. B.autora do projeto de pesquisa do qual este artigo é um recorte. Orientadora do Trabalho de Conclusão de Curso da primeira autora. Foi responsável pela escrita final deste manuscrito.

\section{DECLARAÇÃO DE CONFLITOS DE INTERESSE}

Não há conflitos de interesse no presente artigo.

\section{DECLARAÇÃO DE FINANCIAMENTO}

A pesquisa foi financiada pela Fundação de Amparo à Pesquisa do Estado de São Paulo.

\section{REFERÊNCIAS}

American Psychiatric Association. (2014). Manual Diagnóstico e Estatístico de Transtornos Mentais - DSM-V. $5^{\mathrm{a}}$ Ed. Porto Alegre: Artmed.

Bell, A. F., \& Andersson, E. (2016). The birth experience and women's postnatal depression: A systematic review. Midwifery, 39 (2016), 112-123. doi: 10.1016/j.midw. 2016.04.014

Belli, L. F. (2013). La violencia obstétrica: otra forma de violación a los derechos humanos. Revista Redbioética/ UNESCO, 1 (7): 25-34.

Benincasa, M. (2014). Cesárea Eletiva, Violência Obstétrica e Parto Humanizado: o legado destas intervenções para a vida emocional da mulher.

Biernack, P., \& Waldorf, D. (1981). Snowball Sampling: Problems and Techniques of Chain Referral Sampling. Sociological Methods \& Research, 10 (2), 141-163. doi: 10.1177/004912418101000205

Borsa, J. C. (2007). Considerações acerca da relação MãeBebê da Gestação ao Puerpério. Contemporânea Psicanálise e Transdisciplinaridade, (2).

Brasil - Portal de estatísticas do estado de São Paulo. (2010). Fundação Sistema Estadual de Análise de Dados $-S E A D E$.

Campos, C. J. G. (2004). Método de análise de conteúdo: ferramenta para a análise de dados qualitativos no campo da saúde. Rev. bras. Enferm., 57 (5), 611-614.

Coutinho, M. P. L., \& Saraiva, E. R. A. (2008). Depressão pósparto: considerações teóricas. Estud. pesqui. psicol., 8 (3).

Dennis C. L, \& Dowswell T. (2013). Psychosocial and psychological interventions for preventing postpartum depression. Cochrane Database of Systematic Reviews. doi: 10.1002/14651858.CD001134.pub3

Diniz, S. G., Salgado, H. O., Andrezzo, H. F. A., Carvalho, P. G. C., Carvalho, P. C. A., Aguiar, C. A., \& Niy, D.Y. (2015). Abuse and disrespect in child birthcare as a public health issue in Brazil: origins, definitions, impacts on maternal health, and proposals for its prevention. Journal of Human Growth and Development, 25 (3), 377-384. doi: 10.7322/ jhgd. 106080 


\section{W INERAC̄̈OEM ET PSICOLOGIA}

Greinert, B. R. M., \& Milani, R. G. (2015). Depressão pós-parto: uma compreensão psicossocial. Psicol. teor. prat., 17 (1) 26-36. 2015.

Konradt, C. E., Silva, R. A., Jansen, K., Vianna, D. M., Quevedo, L. A., Souza, L. D. M., Oses, J. P., \& Pinheiro, R. T. (2011) Depressão pós-parto e percepção de suporte social durante a gestação. Rev. psiquiatr. Rio Gd. Sul, 33 (2), 7679.

Lopes, R. C. S., Donelli, T. S., Lima, C. S., \& Piccinini, C. A (2005). 0 antes e o depois: expectativas e experiências de mães sobre o parto. Psicologia: Reflexão e Crítica, 18 (2), 247-254.

Maimburg, R. D., \& Væth, M. (2015). Postpartum depression among first-time mothers - results from a parallel randomized trial. Sexual \& Reproductive Healthcare, 6 (2), 95-100. doi: 10.1016/j.srhc.2015.01.003

Malloy-Diniz, L. F., Schlottfeldt, C. G. M. F., Figueira, P., Neves, F. S., \& Corrêa, H. (2010). Escala de Depressão Pós-Parto de Edimburg: análise fatorial e desenvolvimento de uma versão de seis itens. Rev. Bras. Psiquiatr., 32 (3), 316-318.

Meltzer-Brody, S. (2015). Heterogeneity of postpartum depression: A latent class analysis. Lancet Psychiatry, 2 (1), 59-67. doi: 10.1016/S2215-0366(14)00055-8

Negron, R., Martin, A., Almog, M., Balbierz, A., \& Howell, E. A. (2013). Social support during the postpartum period: Mother's views on needs, expectations, and mobilization of support. Matern Child Health J., 17 (4), 616-623. doi: 10.1007/s10995-012-1037-4.

Ohoka, H., Koide, T., Goto, S., Murase, S., Kanai, A., Masuda, T., Aleksic, B., Ishikawa, N., Furumura, K., \& Ozaki, N. (2014). Effects of maternal depressive symptomatology during pregnancy and the postpartum period on infant-mother attachment. Psychiatry and Clinical Neurosciences, 68, 631-639. doi: 10.1111/pcn.12171

Oliveira, A. S. S., Rodrigues, D. P., Guedes, M. V. C., \& Felipe, G.F. (2010). Percepção de mulheres sobre a vivência do trabalho de parto e parto. Revista Rene, 11, 32-41.

Oliveira, D. C. (2008). Análise de conteúdo temáticocategorial: uma proposta de sistematização. Rev. enferm. UERJ, 16 (4), 569-76.

Carlesso, P. P., Souza, J. R., \& Moraes, A. P. B. (2014). Análise da relação entre depressão materna e indicadores clínicos de risco para o desenvolvimento infantil. Revista CEFAC, 16.

Piccinini, C. A., Gomes, A. G., Moreira, L. E., \& Lopes, R. S. (2004). Expectativas e sentimentos da gestante em relação ao seu bebê. Psic.: Teor. e Pesq., 20 (3), 223-232.
Saraiva, E. R. A., \& Coutinho, M. P. L. (2007). A estrutura das representações sociais de mães puérperas acerca da depressão pós-parto. Psico-USF, 12 (2), 319-326.

Saraiva, E. R. A., \& Coutinho, M. P. L. (2008). O sofrimento psíquico no puerpério: um estudo psicossociológico. Rev. Mal-Estar Subj., 8 (2), 505-527.

Schardosim, J. M., \& Heldt, E. (2011). Escalas de rastreamento para depressão pós-parto: uma revisão sistemática. Rev. Gaúcha Enferm., 32 (1), 159-166.

Schmidt, E. B., Piccoloto, N. M., \& Müller, M. C. (2005). Depressão pós-parto: fatores de risco e repercussões no desenvolvimento infantil. Psico-USF, 10 (1), 61-68.

Schwengber, D. D. S., \& Piccinini, C. A. (2005). A experiência da maternidade no contexto da depressão materna no final do primeiro ano de vida do bebê. Estud. psicol. (Campinas), 22 (2), 143-156.

Schwengber, D. D. S., \& Piccinini, C. A. (2003). O impacto da depressão pós-parto para a interação mãe-bebê. Estud. psicol. (Natal), 8 (3), 403-411. doi: 10.1590/S1413294X2003000300007

Silva, E. T., \& Botti, N. C. L. (2006). Depressão puerperal - uma revisão de literatura. Revista Eletrônica de Enfermagem, 7 (2), 231-238. doi: 10.5216/ree.v7i2.880

Silva, F. C. S., Araújo, T. M., Araújo, M. F. M., Carvalho, C. M. L., \& Caetano, J. Á. (2010). Depressão pós-parto em puérperas: conhecendo interações entre mãe, filho e família. Acta paul. enferm., 23 (3), 411-416. doi: 10.1590/ S0103-21002010000300016.

Silva, L. J., \& Silva, L. R. (2009). Mudanças na vida e no corpo: vivências diante da gravidez na perspectiva afetiva dos pais. Esc. Anna Nery, 13 (2), 393-401.

Tesser, C. D, Knobel, R., Andrezzo, H. F. A., \& Diniz, S. D. (2015). Violência obstétrica e prevenção quaternária: o que é e o que fazer. Res. Bras. Med. Fam. Comunidade, 10 (35), 1-12. doi: 10.5712/rbmfc10(35)1013

Velho, M. B., Santos, E. K. A., \& Collaço, V. S. (2014). Parto normal e cesárea: representações sociais de mulheres que os vivenciaram. Rev. Bras. Enferm., 67 (2), 282-289. doi: 10.5935/0034-7167.20140038.

Vliegen, N., Casalin, S., \& Luyten, P. (2014). The course of postpartum depression: a review of longitudinal studies. Harv. Ver. Psychiatry, 22 (1),1-22. doi: 10.1097/HRP. 0000000000000013

Recebido em: 28/12/2017 Primeira decisão editorial em: 20/04/2018 Aceito em: 13/06/2018 